\title{
Effect of Elevated Temperature on Bending Fatigue Behavior for Neat and Reinforced Polyamide 6,6
}

\author{
Orhan S. Abdullah ${ }^{1 *}$, Shaker S. Hassan ${ }^{2}$, Ahmed N. Al-khazraji ${ }^{3}$
}

\section{Authors affiliations: \\ $\left.1^{*}\right)$ Mechanical Engineering Dept., University of Technology, Baghdad-Iraq. orhanssabah@yahoo.com}

2) Mechanical Engineering Dept., University of Technology,

Baghdad-Iraq.

Shakersakran19521@yahoo.com

3) Mechanical Engineering Dept., University of Technology,

Baghdad-Iraq.

drahmed53@yahoo.com

\section{Paper History:}

Received: $20^{\text {th }}$ Feb. 2020

Revised: $26^{\text {th }}$ March 2020

Accepted: $16^{\text {th }}$ July 2020

\section{Abstract}

Recently, considering polymer composite in manufacturing of mechanical parts can be caused a fatigue failure due to the very long time of exposure to cyclic loading and may at environmental temperatures higher than their glass transition temperature; therefore, in this paper, a comprehensive investigation for bending fatigue behavior at room and elevated temperatures equal to $60{ }^{\circ} \mathrm{C}, 70^{\circ} \mathrm{C}$, and $80{ }^{\circ} \mathrm{C}$ will be done. Rotating bending test machine was manufactured for this purpose supplied with a connected furnace to perform fatigue tests at elevated temperatures. The obtained results appeared that the increase in applied stress and temperature caused a clear reduction in fatigue life; also the addition of carbon nanotubes enhanced the fatigue life at different temperatures by $183 \%, 205 \%, 218 \%$, and $240 \%$, respectively while the addition of short carbon fibers improved fatigue life by $324 \%, 351 \%, 387 \%$, and $415 \%$, respectively. As well as, Polyamide 6,6/carbon fiber composite appeared fatigue limit at temperatures equal to $20^{\circ} \mathrm{C}$ and $60^{\circ} \mathrm{C}$ and stresses approximately equal to $55 \mathrm{MPa}$ and $38 \mathrm{MPa}$ respectively.

Keywords: CNTs, High Cycle Fatigue, Polyamide 6,6, Short Carbon Fibers.

$$
\begin{aligned}
& \text { تاثير درجة الحرارة المرتفعة على سلوك الكلال الانحنائي لمادة البولي أمايد 6,6 } \\
& \text { النقية والمدعمة } \\
& \text { أورهان صباح عبدالله ، شاكر سكران حسن , أحمد نايف الخزرجي }
\end{aligned}
$$

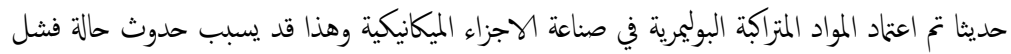

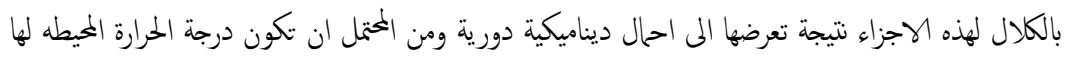

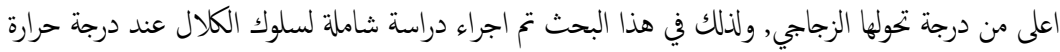

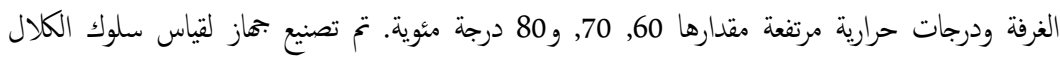

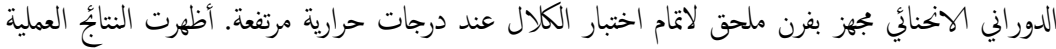

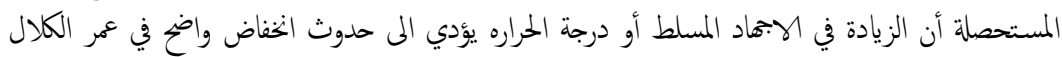

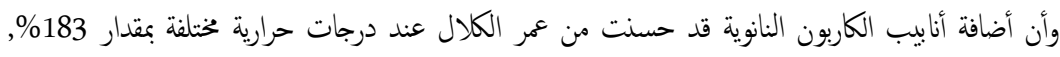

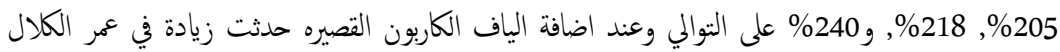

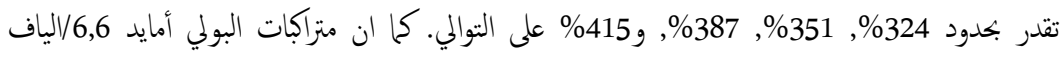

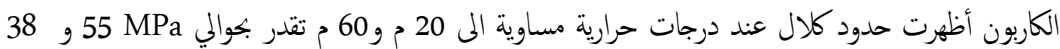

$$
\begin{aligned}
& \text { MPa }
\end{aligned}
$$

\section{Introduction}

Nowadays, the polymer matrix composites are widely considering in industrial applications due to their unique properties as well as their acceptable cost and low weight that will help to save energy [1].
Between all thermoplastic polymer composites, Polyamide 6,6 composites recently have a high interest in the industrial field upon their unexpected mechanical properties and their ability to manufactured in complex shapes, these characteristics

NJES is an open access Journal with ISSN 2521-9154 and eISSN 2521-9162

This work is licensed under a Creative Commons Attribution-NonCommercial 4.0 International License 
made Polyamide 6,6 composites be the highest worldwide production in 2011with two million ton [2].

Polymers and their composites unlike metals in fatigue failure mechanism the crack not initiated due to high stress concentration in localized zone, the failure may be happened due to presence of two or more phases which are causes one of the most probable types of damage mechanism such as; crazing, shear yielding, fiber pull out, delamination, or debonding phenomenon within the interface region between the fiber and the matrix, this made the investigation of fatigue failure in polymers are more complex [3].

As polymer composites recently used in manufacturing of some mechanical parts such as gears, bearings, clutches, etc.., and these parts are mainly severed cyclic loading, as well as polymers have a high tendency to appear a clear deformation especially at temperatures higher than their glass transition temperature, therefore, the investigation of fatigue behavior at room and elevated temperature is more important [4].

One of the most attractive methods used to improve the structural and mechanical properties for polymers is the reinforcement by nanoparticles or fibers; therefore, several previous studies investigated the influence of reinforcement materials and temperature on fatigue behavior in polymers. Raif Sakin et al. [5] investigated the effect of adding woven glass fiber to Polyester resin on bending fatigue behavior under fully reversed loading condition and they observed that fatigue life improved with the addition of woven glass fiber. B. Esmaeillou et al. [6] investigated the fatigue crack initiation in Polyamide 6,6 reinforced with $30 \mathrm{wt} \%$ glass fiber under two type of loading; TensionTension Fatigue (TTF) with stress ratio $\mathrm{R}=0.1,0.3$ and Alternative Flexural Fatigue (AFF) with $(\mathrm{R}=-1)$ under different test frequencies, the results indicate that the prepared materials have a better AFF resistance and increasing the test frequency higher than $20 \mathrm{~Hz}$ leads to generate heat during the test duration. Z. H. Zhang and N. Yu [7] studied the effect of stress concentration and reinforcement materials on rotating bending fatigue behavior for neat and reinforced Epoxy with $0.5 \%$ wt of $\mathrm{CNT}_{\mathrm{S}}$. The results appeared that the presence of $\mathrm{CNT}_{\mathrm{S}}$ in the Epoxy matrix structure eliminates the influence of the notch effect on fatigue life. Yi-Ming and Huang [8] studied the effect of $\mathrm{CNT}_{\mathrm{S}}$ content on tensile strength and fatigue performance of MWCNTs /Epoxy composites under variant test temperatures. The results showed that the increase in temperature leads to decreases tensile strength and fatigue life for neat and reinforced Epoxy and any increase in $\mathrm{CNT}_{\mathrm{S}}$ content higher than $1 \%$ wt has a limited effect in improving fatigue life. Amélie et al. [9] demonstrated the influence of woven glass fiber orientation on tensile and fatigue performance for Polyamide 6,6 composite. The results indicated that oriented of the three glass fiber layers with $(0 / 90)$ direction gives the highest improvement in tensile strength and the longest fatigue life as well as, the increase in testing temperature decrease fatigue life. Elouni Chebbi et al. [10] studies the influence of addition short glass fiber with 20 , and $30 \mathrm{wt} \%$ as a reinforcement material to Polyamide 6,6 on fatigue resistance, the results showed that the increase in fiber content improved the fatigue resistance. Jozsef and Laszlo [11] studied the effect of adding carbon fiber and basalt fiber with 10,20, and $30 \mathrm{wt} \%$ to Polyamide 6 on tensile strength, fatigue and creep behavior. The results appeared that the addition of $30 \%$ carbon fiber leads to increase the tensile strength by $164 \%$ in comparison to neat Polyamide 6 . As well as, the carbon fiber exhibited a better fatigue performance than basalt fiber at each stress level and fiber content. C. Capela et al. [12] studied the fatigue behavior of Epoxy-based composite reinforced with carbon fiber with variant volume fraction within 5-20\% with $500 \mu \mathrm{m}$ length. The results denoted an improvement in fatigue strength, tensile strength, and stiffness attendant to fiber volume fraction increasing up to $17.5 \%$ by $140 \%$, $52 \%$, and $400 \%$ respectively but afterward, all the mechanical properties were slightly reduced. $\mathbf{M}$. Bondy et al. [13] investigated the effect of fiber orientation on the fatigue behavior for nylon 6,6 reinforced with $40 \mathrm{wt} \%$ long carbon fiber oriented in three different flow angles $0^{\circ}, 45^{\circ}$, and $90^{\circ}$. The results indicated that the increase in fiber flow angle causes a high reduction in fatigue stress level at $10^{6}$ cycles by $48 \%$ and $98 \%$ at $45^{\circ}$ and $90^{\circ}$ respectively in comparison to the $0^{\circ}$ flow angle.

As a result of the above reviews, it can be noticed that few investigations were employed on fatigue behavior for Polyamide 6,6 reinforced with short carbon fibers or $\mathrm{CNT}_{\mathrm{S}}$, therefore, in the present work, an experimental study for bending fatigue behavior at room and elevated temperatures higher than the glass transition temperature will be done for neat and reinforced Polyamide 6,6.

\section{Experimental Details}

\subsection{Materials}

Neat and reinforced Polyamide 6,6 with 1\% wt $\mathrm{CNT}_{\mathrm{S}}$ or $30 \%$ wt short carbon fibers are supplied from Guangzhou engineering plastic industries (group) Co., Ltd., were considered in prepared for bending fatigue test specimen.

\subsection{Composite Preparation}

Beside neat Polyamide 6,6, two types of Polyamide 6,6 composites were prepared; the first includes $1 \%$ wt $\mathrm{CNT}_{\mathrm{S}}$ with (purity :> 95\%, diameter: 20-25 nm, length: 25-40 $\mu \mathrm{m}$ ) while the second content $30 \%$ wt of short carbon fiber with (diameter: $10 \mu \mathrm{m}$, average length $260 \mu \mathrm{m}$ ). The two composites and neat Polyamide 6,6 molded by injection technique in a rod shape with $120 \mathrm{~mm}$ diameter and $750 \mathrm{~mm}$ length in Guangzhou engineering plastic industries (group) Co., Ltd. (China), by considering a two stage injection molding machine in order obtain a homogenous distribution of reinforced materials inside the composite. 


\subsection{Experimental Fatigue Test}

To predict the rotating bending fatigue behavior in Polyamide 6,6 and their composites at room and elevated temperatures, a rotating bending test machine were manufactured for this purpose as shown in Figure (1). The machine consist of rotating motor with 1200 RPM, two supporting bearing, rotating shaft, digital loading system, laser sensor, counter, thermocouple, digital thermal control board, and small furnace with suitable dimensions made of double steel sheets and multi insulated layers of woven glass fiber to prevent heat leakage and keep excellent insolation as well, An electrical heater of $2000 \mathrm{~W}$ was included inside the furnace with a Ktype thermocouple to control the heating temperature inside the furnace connected to the digital thermal control board.. In contrast, the test specimens prepared according to ASTM E606 Fatigue test specimen as shown in Figure (2) [14].

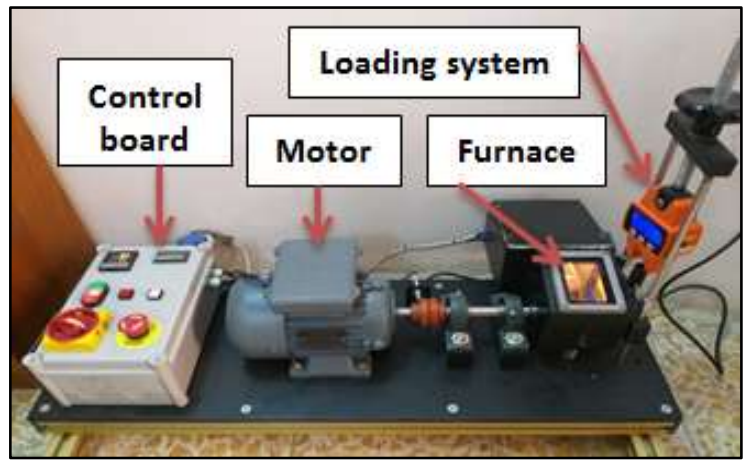

Figure (1): Fatigue test machine.

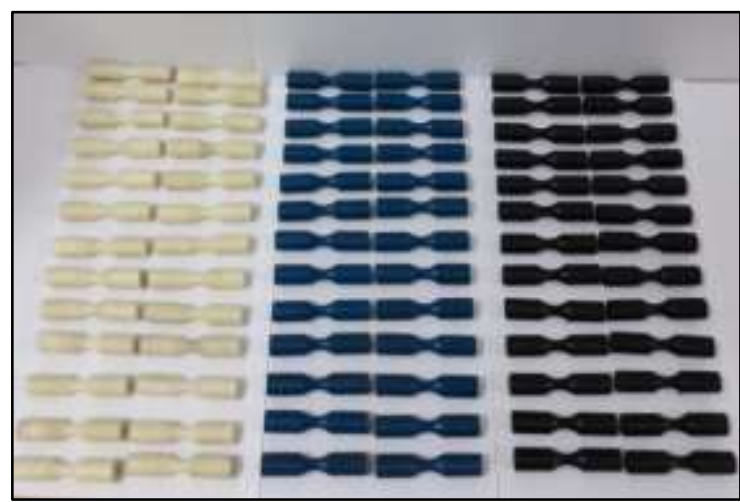

Figure (2): Fatigue test specimens.

\section{Theoretical Considerations}

Generally, fatigue failure occurs in polymers and their composites by one of the following probable modes: mechanically dominated mechanism or thermally dominated mechanism. A mechanically dominated mechanism includes crack initiation and subsequent by crack propagation due to crazing or shear yielding until the crack length reached the critical length then the final failure has happened. This failure scenario occurs when the applied stress or frequency is relatively low and the resultant fatigue life is high, this regime has frequently known as the high cycle fatigue regime. Mostly, the polymers and their composites at this regime displayed brittle failure mode. On the other hand, at higher levels of applied stresses or frequencies, the mechanical and the physical properties of polymers are affected by hysteretic heating that generated due to dynamic loading and their low thermal conductivity. In fact, polymers have a weak heat dissipation to the surrounding which caused rising polymer temperature during the test. The failure at this regime is ductile with lower fatigue life and named low cycle fatigue regime; due to the hysteretic heating effect, the failure mode can be considered as a thermally dominated mechanism [15].

As metals, polymers and their composite fatigue data can be displayed in ( $\mathrm{S}-\mathrm{N})$ curve by plots the amplitude stress $\left(\sigma_{\mathrm{a}}\right)$ versus the number of cycles to failure $\left(\mathrm{N}_{\mathrm{f}}\right)$, this curve can also be presented in logarithmic or semi-logarithmic scales. Basquin's equation defined the S-N curve as follows [16]:

$$
\sigma=\alpha N_{f}^{b}
$$

Where: $\alpha$ and $b$ are constants that obtained by linearization equation (1) and written in a logarithmic form as following:

$$
\log \sigma=\log \alpha+b \log N_{f}
$$

\section{Results and Discussion}

To predict the influence of applied stress and temperature on fatigue life; a high cycle fatigue test was performed for Polyamide 6,6 and their composites at room and an elevated temperature under a range of stresses varies between $40 \%$ to $90 \%$ of the yield stresses. Three fatigue test specimens were tested at each stress level and the average value of $\mathrm{N}_{\mathrm{f}}$ was considered. As it proved in several previous researches, Polyamide 6,6 as other thermoplastics do not have a clear fatigue limit, therefore, if the test specimen exceeded $10^{6}$ cycles without failure then it can be considered this stress level as a fatigue limit.

As presented in Figures (3) to (6) it can be recognized that any increase in temperature or applied stress leads to reduce the number of cycles to failure and fatigue resistance, this agrees with many past literatures deals with fatigue in polymers $[7,8$, \&11]. On the other hand, the usage of carbon nanotubes improved the fatigue resistance in Polyamide 6,6 by increasing fatigue life at different test temperatures by $183 \%, 205 \%, 218 \%$, and $240 \%$ respectively. Moreover, the addition of carbon fibers made a clear improvement in fatigue resistance by increasing the number of cycles to failure at all testing temperatures by $324 \%, 351 \%, 387 \%$, and $415 \%$ respectively. As well as a carbon fiber/Polyamide 6,6 composites appeared a fatigue limit at temperatures equal to $20^{\circ} \mathrm{C}$ and $60^{\circ} \mathrm{C}$ and stresses approximately equal to $55 \mathrm{MPa}$ and $38 \mathrm{MPa}$ respectively. Therefore, any applied stress equals to or less than the previous fatigue limit values does not cause fatigue failure. 


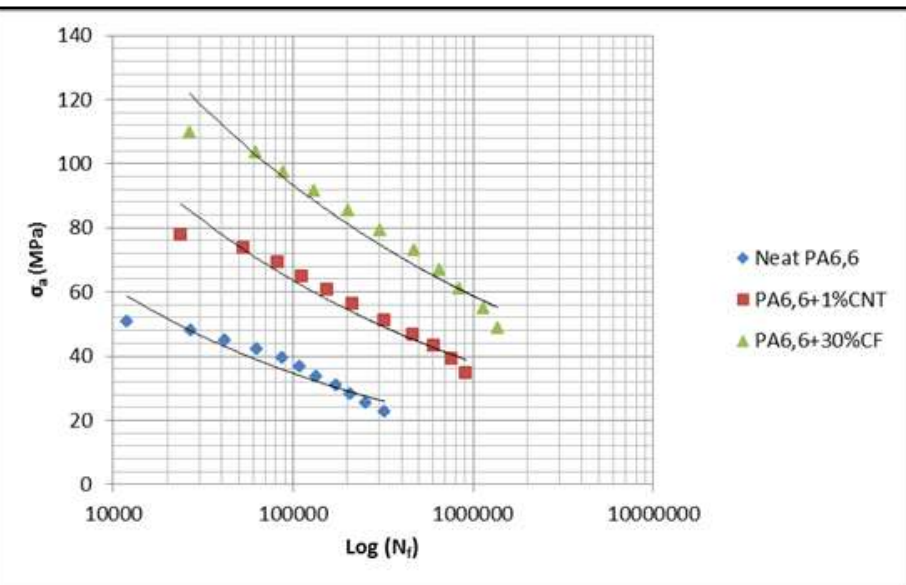

Figure (3): S-N curves for neat and reinforced Polyamide 6,6 at $20^{\circ} \mathrm{C}$.

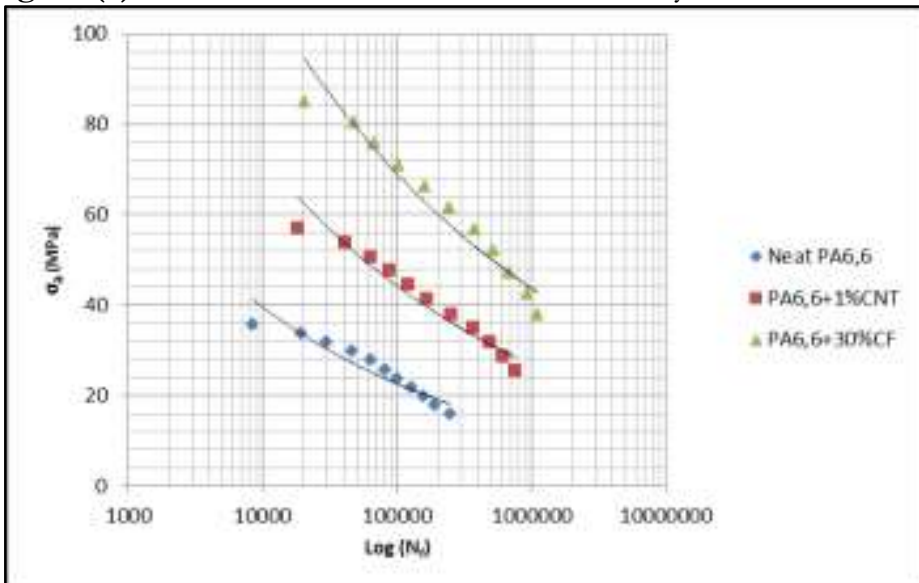

Figure (4): S-N curves for neat and reinforced Polyamide 6,6 at $60^{\circ} \mathrm{C}$.

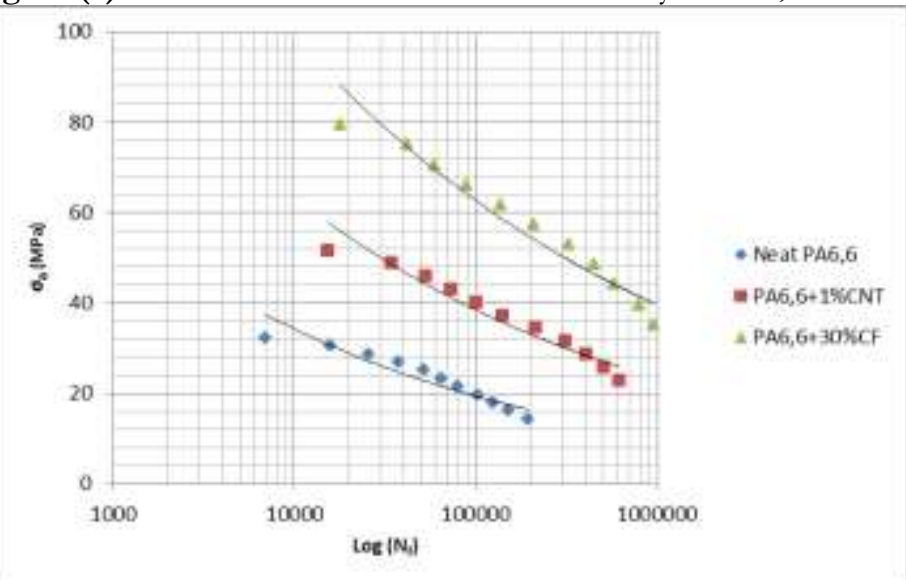

Figure (5): S-N curves for neat and reinforced Polyamide 6,6 at $70^{\circ} \mathrm{C}$

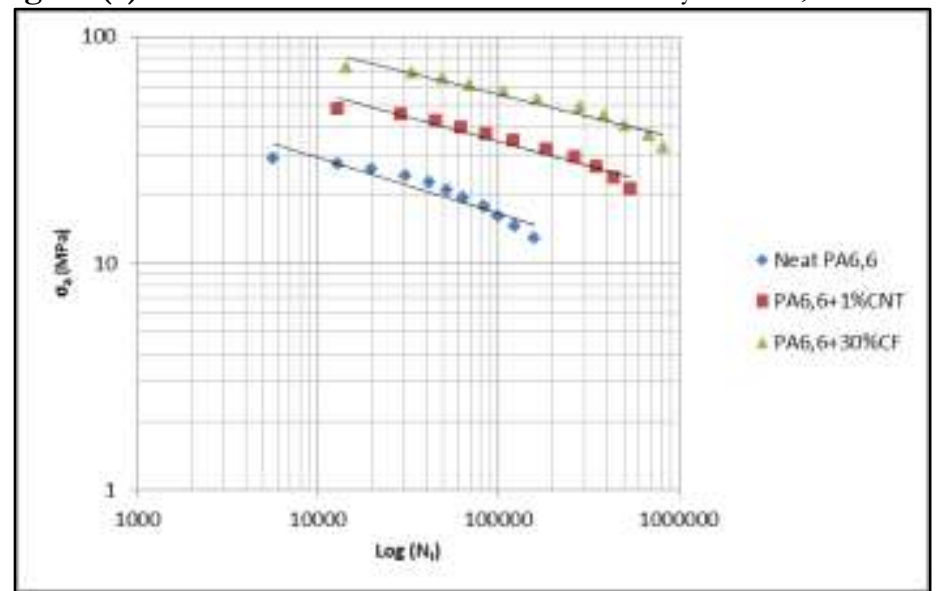

Figure (6): S-N curves for neat and reinforced Polyamide 6,6 at $80^{\circ} \mathrm{C}$. 
The values of fatigue parameters $\alpha$ and $b$ that obtained by linearized Basquin's equation are listed in Table (1) where $\alpha$ represents the intercept in MPa and $\mathrm{b}$ is the slope of the fitting line.

The Variation in $\alpha$ and $b$ with temperature are shown in Figures (7) and (8), the intercept decreases linearly with temperatures, while, slope appeared almost constant linear behavior with variation in testing temperature. This observation has a high agreement with the finding of M. Eftekhari and A. Fatemi [17] and K. Noda et al. [18] when investigated the influence of temperature on fatigue parameters of short glass fiber/Polyamide 6,6 composites.

Table (1): The Influence of additives and temperature on the S-N curves parameters.

\begin{tabular}{|c|c|c|c|c|}
\hline Temperature & Materials & $\alpha$ & b & $\mathbf{R}^{2}$ \\
\hline \multirow{3}{*}{$20^{\circ} \mathrm{C}$} & PA6,6 & 607.69 & -0.249 & 0.8943 \\
\hline & PA6,6 + 1\%CNT & 828.61 & -0.223 & 0.9453 \\
\hline & PA6,6 + 30\%CF & 948.02 & -0.201 & 0.9394 \\
\hline \multirow{3}{*}{$60^{\circ} \mathrm{C}$} & PA6,6 & 372.07 & -0.243 & 0.8962 \\
\hline & PA6,6 + 1\%CNT & 534.49 & -0.217 & 0.9421 \\
\hline & PA6,6 + 30\%CF & 677.11 & -0.198 & 0.9413 \\
\hline \multirow{3}{*}{$70^{\circ} \mathrm{C}$} & PA6,6 & 334.17 & -0.245 & 0.8949 \\
\hline & PA6,6 + 1\%CNT & 470.09 & -0.217 & 0.9408 \\
\hline & PA6,6 + 30\%CF & 566.88 & -0.195 & 0.9437 \\
\hline \multirow{3}{*}{$80^{\circ} \mathrm{C}$} & PA6,6 & 284.23 & -0.247 & 0.8963 \\
\hline & PA6,6 + 1\%CNT & 414.41 & -0.216 & 0.9423 \\
\hline & PA6,6 + 30\%CF & 517.67 & -0.192 & 0.9554 \\
\hline
\end{tabular}

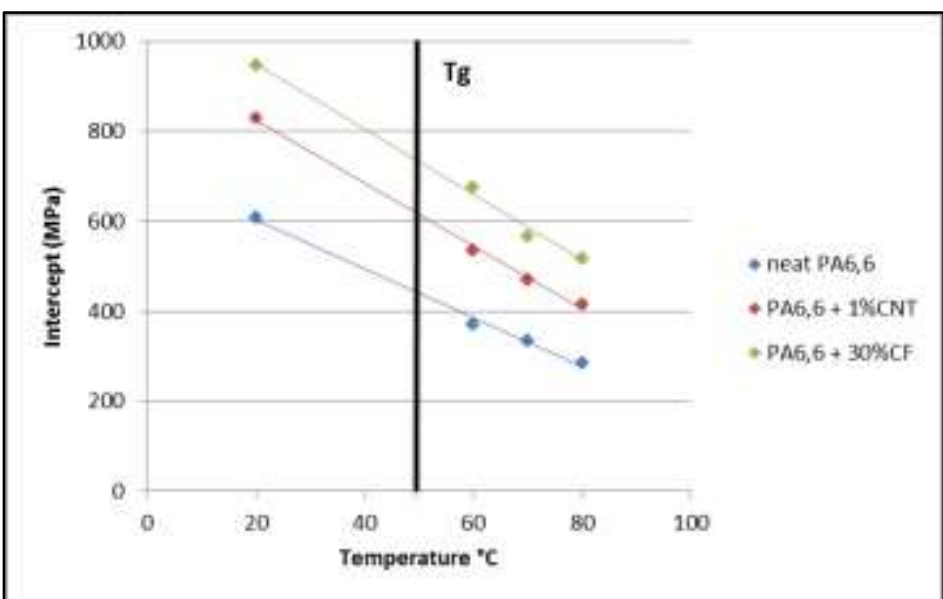

Figure (7): The influence of temperature on Intercept for Polyamide 6,6 and their composites at several temperatures.

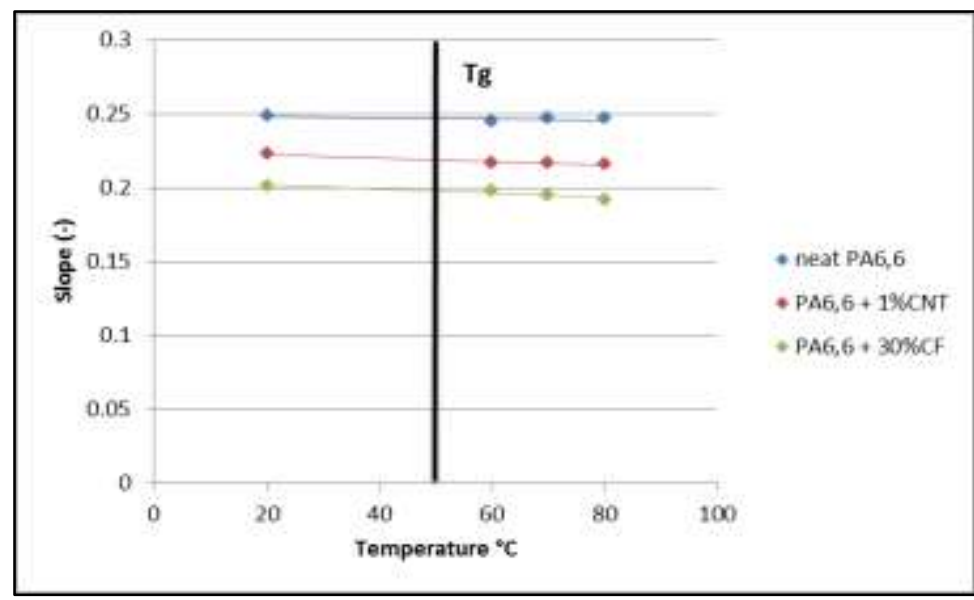

Figure (8): The influence of temperature on slope for Polyamide 6,6 and their composites at several temperatures. 


\section{Conclusions}

From the experimental results of fatigue behavior at variant temperatures equal to $20^{\circ} \mathrm{C}, 60^{\circ} \mathrm{C}, 70^{\circ} \mathrm{C}$, and $80^{\circ} \mathrm{C}$, it can be concluding the following points:

1) The addition of carbon nanotubes improved fatigue life at different test temperatures by $183 \%$, $205 \%, 218 \%$, and $240 \%$ respectively while the addition of short carbon fiber improved fatigue life by $324 \%, \quad 351 \%, \quad 387 \%$, and $415 \%$ respectively.

2) The increase in amplitude stress values and testing temperatures leads to decrease fatigue resistance especially in neat Polyamide 6,6.

3) The experimental results indicate the usage of short carbon fibers as a reinforcement material to Polyamide 6,6 appeared the highest tensile strength and fatigue life, and the only composite have a fatigue limit equals $55 \mathrm{MPa}$ and $38 \mathrm{MPa}$ at $20^{\circ} \mathrm{C}$ and $60{ }^{\circ} \mathrm{C}$ respectively.

4) The intercept value $(\alpha)$ decreases linearly with temperatures, while, slope (b) appeared almost constant linear behavior with variation in testing temperature.

\section{References}

[1] Ujjwal Makkar, Mrinalini Rana, and Amritpreet Singh, 'Analysis of fatigue behavior of glass/carbon fiber epoxy composite', International Journal of Research in Engineering and Technology, vol.4, no.4, 2015.

[2] M. Biron, 'Thermoplastics and Thermoplastic Composites',Second Edition, Willim Andrew puplisher, 2012.

[3] M. Knez, S. Glode, M. Ruika, and J. Kramberger, 'A rotating bending approach for determination of low-cycle fatigue parameters', Int. J. Fatigue, vol. 32, no. 10, pp. 1724-1730, 2010.

[4] A. F. Aguirre, M. Oliva, R. T. Schoephoerster, and V. A. Kasyanov, 'Static and Dynamic Mechanical Testing of a Polymer With Potential Use As Heart Valve Material', Summer Bioeng. Conf. June 25-29, Sonesta Beach Resort Key Biscayne, Florida, no. 1, pp. 2-3, 2003.

[5] Raif Sakin,_Irfan Ay, and Ramazan Yaman, 'An investigation of bending fatigue behavior for glassfiber reinforced polyester composite materials', Materials and design, vol. 29, pp. 212-217, 2008.

[6] B. Esmaeillou et al., 'Fatigue Behavior of Polyamide 66 / Glass Fiber Under Various Kinds of Applied Load', Science Arts \& Métiers ( SAM ), 2015.
[7] Z. H. Zhang and N. Yu, 'Fatigue of carbon nanotube-reinforced composites', Adv. Mater. Res., vol. 446-449, pp. 3128-3131, 2012.

[8] Y. M. Jen and C. Y. Huang, 'Static and fatigue strengths of carbon nanotube/epoxy composites under hygrothermal environments', Appl. Mech. Mater., vol. 284-287, pp. 204-210, 2013.

[9] A. Malpot, F. Touchard, and S. Bergamo, 'Fatigue Behaviour of a Thermoplastic Composite Reinforced with Woven Glass Fibres for Automotive Application', Procedia Eng., vol. 133, pp. 136-147, 2015.

[10] E. Chebbi, J. Mars, M. Wali, and F. Dammak, 'Fatigue behavior of short glass fiber reinforced polyamide 66: Experimental study and fatigue damage modelling', Period. Polytech. Mech. Eng., vol. 60, no. 4, pp. 247-255, 2016.

[11] J. Szakács and L. Mészáros, 'Effect of fiber contents on fatigue behavior of injection molded polyamide 6 matrix composites', Period. Polytech. Mech. Eng., vol. 61, no. 1, pp. 74-78, 2017.

[12] C. Capela, S. E. Oliveira, and J. A. M. Ferreira, 'Fatigue behavior of short carbon fiber reinforced epoxy composites', Compos. Part B Eng., vol. 164, pp. 191-197, 2019.

[13] M. Bondy, W. Rodgers, and W. Altenhof, 'Tensile fatigue characterization of polyamide 66/carbon fiber direct/in-line compounded long fiber thermoplastic composites', Compos. Part B Eng., vol. 173, no. February, 2019.

[14] ASTM E-606 'Standard recommended practice for constant-amplitude fatigue test', ASTM International, West Conshohocken, PA; 2006.

[15] G. Wrobel, 'A computer model of the process of polymer materials fatigue destruction',Journal of Achievements in materials and manufacturing engineering, Vol.42, issue 1-2, 2010.

[16] Budynas Nisbett, 'Shigley's Mechanical Engineering Design', Eighth edition, McGraw-Hill Primis, 2014.

[17] M. Eftekhari and A. Fatemi, 'Creep behavior and modeling of neat, talc-filled, and short glass fiber reinforced thermoplastics', Compos. Part B Eng., vol. 97, pp. 68-83, 2016.

[18] K. Noda, A. Takahara, and T. Kajiyama, 'Fatigue failure mechanisms of short glass-fiber reinforced nylon 66 based on nonlinear dynamic viscoelastic measurement', Polymer, Vol. 42, No. 13, pp.58035811,2001 